\title{
Exploration on Intelligent Teaching of Probability and Statistics in Universities
}

\author{
Wen Ye* Yong Zhang Chunming Xu \\ School of Mathematics and Statistics, Yancheng Teachers University, Jiangsu 224002, China \\ * E-mail of the corresponding author: yewen0105@sci.edu.rs
}

The research is part of the achievements of the research project of higher education reform in Jiangsu Province.No.2019JSJG257(Sponsoring information)

\section{Abstract}

Starting from the concept of Intelligent Teaching, this paper briefly introduces the meaning of intelligent classroom, then gives the description about tools of Intelligent teaching. Taking Probability and Statistics as an example, this paper explores the mild Intelligent teaching with Mosotech as the tool of Intelligent teaching which can be used before, during and after class under the Intelligent teaching mode.

Keywords: Intelligent teaching, Intelligent teaching tools, Probability and statistics

DOI: $10.7176 / \mathrm{JEP} / 12-27-03$

Publication date:September $30^{\text {th }} 2021$

\section{Intelligent teaching}

Although there are many studies on intelligent teaching at present, a strict definition is lacking. The author thinks that the following statements are more appropriate. To put it simply, intelligent teaching is an intelligent teaching mode implemented by the new generation of information technology such as artificial intelligence and mobile Internet. Among them, intelligent classroom teaching is a teaching mode which is studied more in intelligent teaching. Intelligent Class aims at cultivating talents with high intelligence and creativity. It relies on artificial intelligence, big data, learning analytics and other technologies. It can implement learning diagnosis and analysis, provide intelligent resources, and carry out 'cloud + terminal' learning activities and support services. It is a new class for recording learning process and evaluating multiple intelligences (Qiu Yi 2018). The intelligent classroom based on the Internet of things can effectively solve the power and network problems of mobile terminals (Chen Li 2019). Intelligent classroom has scientific attributes, technical attributes, cultural attributes, and social attributes (Wang Tianping 2019).

In December 2019, Anhui Provincial Education Department, Shanghai Municipal Education Commission, Zhejiang Provincial Education Department and Jiangsu Provincial Education Department jointly held the first Yangtze River Delta Teachers' Intelligent Teaching Competition. The participating teachers improved the traditional teaching mode and played a better role in guiding the implementation of intelligent teaching by rationally using intelligent teaching tools and adopting mixed teaching methods. This paper studies the implementation of intelligent teaching in the whole teaching process rather than limited to classroom teaching. Intelligent classroom teaching relies on intelligent classroom, but at present, intelligent classroom has not reached the degree of popularization in colleges and universities. Therefore, the mild intelligent classroom teaching achieved by using intelligent teaching tools has great promotion value, which can be used to transform the traditional classroom teaching.

\section{Intelligent teaching tools}

Intelligent teaching tools are cloud service platforms that use smart devices such as smart phones and tablet computers to carry out timely feedback interactive teaching inside and outside the classroom under the mobile network environment (Tai Wen 2021), including Mosotech, Rain classroom, MOOC, etc. In practice, author often uses Mosotech to carry out daily teaching activities. Intelligent teaching tools generally have the following characteristics:

- Simple management and operation

Teachers create one or more classes according to teaching needs, and students use the corresponding invitation code to join the class. Teachers can manage students in a class in groups. After that, students can study anytime and anywhere. Teachers can easily manage classes, inform information, share resources, and conduct activities from any device.

- $\quad$ Rich course resources

Teachers can upload micro-videos, PowerPoint courseware, documents, pictures, audio, and other rich teaching resources to the course platform. In addition, interactive teaching activities such as discussion, Q\&A, online testing, voting questionnaire and brainstorming can be carried out at any time.

- Clear data analysis

Student check-in, homework submission, mutual evaluation and other operations can be completed on 
the platform. Every learning behavior of students is recorded in the background of intelligent teaching tools. Teachers can track students' learning progress and situation at any time and evaluate students' learning effectiveness in time.

\section{Intelligent teaching practice of Probability and Statistics}

According to the regularity of random phenomena, Probability and Statistics objectively makes an objective quantitative definition of the likelihood of an outcome, which is a course for deductive research on the statistical regularity of random phenomenon. It is not only a public basic course for science and technology majors in colleges and universities, but also a common professional course for mathematics majors.

At present, the teaching mode of mathematics courses in colleges and universities is still based on the traditional teaching mode, with teachers unilaterally filling teaching and students passively accepting knowledge. Because the contents of this course are various and abstract, students lack interest in study. So, the quality of the traditional classroom is restricted. In the teaching process of Probability and Statistics, the author adopts the intelligent teaching mode and takes Mosotech as the intelligent teaching tool to carry out mild intelligent teaching. The teaching mode of this course based on Mosotech is mainly composed of three links: intelligent preview, intelligent class, and intelligent consolidation.

\subsection{Intelligent preview}

College mathematics courses have a wide range of knowledge points and are relatively abstract. Students often miss some important points if they only rely on the teaching time in class. Therefore, preview is an essential part of the teaching process. Teachers can make full use of intelligent teaching tools according to teaching requirements. They usually make micro-lesson videos or PowerPoint for students to preview into the course platform in advance. Teachers can master students' preview through small tests, sort out common problems among students, and then make corresponding adjustments to the teaching content in class.

For example, in the section of Bayesian formula in conditional Probability. If students only read the definitions and formulas in books in the traditional way of preview, it is often difficult for them to understand and apply the literal meaning. Therefore, it cannot reach the expected preview effect of teachers. By using Mosotech, teachers can transmit knowledge points to students more intuitively and stimulate students' interest in learning through short and concise micro-lesson videos combined with cases in real life.

\subsection{Intelligent class}

The teaching in class is no longer like the traditional teaching mode which completes the rapid transfer of knowledge. Instead, based on teachers' analysis of students' pre-class self-study, effective classroom activities and evaluation strategies are designed. Teachers can understand students' learning situation in real time by organizing and carrying out various teaching activities such as class discussion, brainstorming and in-class tests. Through the multi-dimensional process evaluation of students, make the evaluation results more objective, and effectively guide students to take the initiative to complete the internalization of knowledge.

3.2.1 Quick and effective sign-in

The use of intelligent teaching tools can greatly improve the problems that teachers generally have in large class teaching, such as missing points, substituting points and long time for sign-in. With Mosotech, teachers can open one-click sign-in or set gesture password for sign-in. After signing in, the distance between each student and the teacher can be displayed on the mobile phone, and it becomes clear whether the student is signed in the class.

3.2.2 Rich and varied activities

Teachers can arrange discussion sessions according to the course progress. For example, when learning the definition of frequency and probability in Chapter 1, teachers can ask questions such as 'Can probability be expressed in the limit form of frequency?' on the platform. Students form their own understanding after full thinking and complete the process from input to output of language. Teachers can make comments or answer questions according to the quality of answers, which can promote students to analyze difficult problems and improve their comprehensive ability.

What's more, teachers can set up a small test related to the course content before class and start the test at any time in the course to check the learning situation of students. Make feedback and evaluation on students' knowledge through the answer results, so that mobile phones can become a tool to assist students in learning. The results of the in-class test will be well retained in the software, which can be used as an important basis for students' normal process assessment.

3.2.3 Positive and enthusiastic atmosphere

Obscure mathematical formulas and theorems in Probability and Statistics will make students feel tired after a long time of teaching. The random selection mode or race-response mode in Mosotech can solve this problem well. Teachers can start the activity at any time according to the teaching needs, and then randomly select a student to answer or start the random answer by shaking the mobile phone. Then students will get the 
corresponding points after the answer. Activities can help teachers active classroom atmosphere in necessary appropriate and mobilize the enthusiasm of students, Let students' attention back to the classroom, so as to effectively improve the quality of the classroom.

Traditional classroom teaching is dominated by teachers. As the object of indoctrination, students can only passively accept knowledge. With the use of intelligent teaching tools, classroom teaching has gradually evolved into a student-centered teaching. Whether random candidates answer questions or set some small voting will greatly enhance the fun of the class and students' sense of participation, to stimulate students' enthusiasm for learning.

\subsection{Intelligent consolidation}

Complicated formulas and theorems are obstacles for students to learn in class. Intelligent teaching tools provide a convenient platform for students to review after class. Teachers can upload some learning materials and courseware which are not limited to books at any time. Also, they can communicate and discuss with students about the content in doubt.

The correction of students' homework is an important part of teachers' responsibility. The feedback and evaluation given in traditional teaching are lagging. 'Mosotech' can automatically correct objective questions and provide answer analysis based on the content set. Teacher divided the problem solving into several interrelated objective problems, so that students could get timely feedback and make modifications after submitting the homework. At the same time, Mosotech can provide detailed analysis of answer data, including answer completion rate, answer accuracy rate and score distribution. By analyzing these data, teachers can timely grasp the learning situation of each student. By the targeted review and guidance to students, teaching methods can be improved, teaching content can be adjusted, and teaching system can be improved.

\section{Conclusion}

The combination of modern information technology, network technology and education produce intelligent teaching, which reflects the development trend of future education and helps to solve the related problems brought by traditional education (Liu Bangqi 2019). Intelligent teaching mode is a new education mode developed to cater for social development and progress of the new ear, is the use of information technology and Internet technology to the development of education and training. Students can learn from their interests and curiosity, while teachers can achieve better teaching results with the help of big data technology and equipment. Integrating Mosotech into Probability and Statistics can greatly promote students' enthusiasm for learning, make students change their passiveness to initiative, cultivate students' ability of independent learning, improve the teaching mode of the course, and thus improve the teaching effect. As teachers in the new era, we must actively follow the trend of the era and accept new technologies. We must recognize the link between education and technology, and teachers should take modern educational technology as the basis for developing intelligent teaching and improving teaching efficiency.

\section{References}

Qiu Yi, Xie Youru, Li Shijie, Li Jia. (2018) Classroom Reform Towards Smart Age[J]. e-Education Research 39(07):70-76.

Chen Li, Xiaoqing Zhong, Jianyong Cai. (2019) Research on Intelligent Teaching Method under the Background of "Internet+"[J]. Journal of Innovation and Social Science Research 6(7):

Wang Tianping, Yan Junzi. (2019) Concept Interpretation and Essential Attributes of Smart Classroom[J]. $e-$ Education Research 40(11):21-27.

Tai Wen. (2021) Research on Application of Cloud-based Flipped Classroom in Java Program Design Courses[J]. Journal of Tianjin Vocational Institutes 23(06): 96-100.

Liu Bangqi. (2019) Development, Platform Architecture and Application Design of Smart Class-From Smart Class 1.0 to Smart Class 3.0[J]. Modern Educational Technology 29(03):18-24. 